\title{
Análise do policy cycle da política nacional de habitação de interesse social: contribuições de gestores municipais de habitação em Minas Gerais
}

\author{
Analysis of the policy cycle of the national policy of housing of social interest: \\ contributions of the municipal housing managers in Minas Gerais
}

Alexandre Matos Drumond[a] (D), Lucas Pazolini Dias Rodrigues[b,c] (1)

\author{
[a] Centro Federal de Educação Tecnológica Celso Suckow da Fonseca (CEFET), Valença, RJ, Brasil \\ [b] Faculdade Dinâmica do Vale do Piranga, Ponte Nova, MG, Brasil \\ [c] Universidade Federal de Viçosa (UFV), Programa de Pós-graduação em Administração, Viçosa, MG, Brasil
}

Como citar: Drumond, A. M., \& Rodrigues, L. P. D. (2019). Análise do policy cycle da política nacional de habitação de interesse social: contribuições de gestores municipais de habitação em Minas Gerais. urbe. Revista Brasileira de Gestão Urbana, 11, e20180141. https://doi.org/10.1590/2175-3369.011.e20180141

\section{Resumo}

Neste artigo, analisa-se a Política Nacional de Habitação de Interesse Social (PNHIS) com base na teoria do policy cycle, a partir de contribuições empíricas de 59 gestores municipais de habitação de Minas Gerais. Buscou-se compreender o ciclo de tal política e verificar seus aspectos positivos e suas falhas. Assim, elaborou-se um questionário com temas referentes à situação habitacional do país, às características dos programas que compõem a PNHIS, ao processo de implementação e ao monitoramento e à avaliação dessa política. Os gestores perceberam que a habitação de interesse social era uma das prioridades do governo, porém os programas existentes não atendiam às especificidades locais e às demandas das famílias. Quanto à implementação, as principais falhas diziam respeito ao excesso de burocracia para acessar os recursos e à baixa qualidade e quantidade de capacitações oferecidas. Em relação à avaliação e ao monitoramento, eram perceptíveis a exigência de relatórios para prestação de contas e a participação dos conselhos durante a execução dos empreendimentos, todavia questionou-se sua efetividade. 0 estudo contribui com reflexões sobre as modalidades dos programas habitacionais, a fim de que as especificidades locais sejam incorporadas, o número de cômodos produzidos seja ampliado e o Sistema de Informação, Monitoramento e Avaliação da Habitação seja instituído.

Palavras-chave: Ciclo de políticas públicas. Habitação. Políticas públicas.

\section{Abstract}

This article analyzes the National Policy on Social Interest Housing (PNHIS) based on the policy cycle theory, from the empirical contributions of 59 municipal housing managers in Minas Gerais. It was sought to understand the cycle of such a Policy and to check its positive aspects and its failures. Thus, a questionnaire was prepared with topics related to the country's housing situation, the characteristics of the programs that make up the PNHIS, the implementation process, and the monitoring and evaluation of this policy. Managers realized that social housing is one of the government's priorities, but existing 
programs do not meet local specificities and the demands of the families. Regarding implementation, the main failures are the excess of bureaucracy to access resources and the low quality and quantity of training offered. Regarding the evaluation and monitoring, it is noticeable the requirement of reports for accountability and the participation of the councils during the execution of the projects. However, their effectiveness is questioned. The study contributed with reflections on the modalities of the housing programs, so the local specificities are incorporated, to increase the number of rooms produced, and to institute the Information System, Monitoring and Evaluation of Housing.

Keywords: Policy cycle. Housing. Public policy.

\section{Introdução}

A habitação é uma demanda antiga no Brasil, de modo que, durante a década de 1940, intensificou-se, segundo Bonduki (2004), a crise habitacional em decorrência do rápido e crescente movimento migratório para o meio urbano. A partir desse período, ações diversas foram implementadas, porém estiveram vinculadas, institucional e financeiramente, a dois órgãos: Fundação Casa Popular (FCP), a partir de 1946, e Banco Nacional de Habitação (BNH), a partir de 1964. Por causa das dificuldades em termos de operacionalização, captação e aplicação perene de recursos, ambos foram extintos (Carneiro \& Souza, 2007; Yoshimura, 2004).

Após a extinção do BNH em 1986, percebeu-se o movimento de setores da sociedade em prol da questão habitacional. A elaboração do Projeto de lei no 2.710/1992, de iniciativa popular, que reivindicava a criação de um fundo nacional para subsidiar investimentos em moradias populares, demonstra tal preocupação da sociedade.

No âmbito governamental, a primeira grande mobilização no sentido de reconhecer a importância da demanda habitacional e incorporá-la à agenda de governo ocorreu no ano 2003, com a criação do Ministério das Cidades, o qual deveria elaborar e coordenar a política de desenvolvimento urbano e as políticas setoriais de habitação, saneamento ambiental, transporte urbano e trânsito (Brasil, 2004).

Fundamentado nesse órgão, foi elaborada e instituída a Política Nacional de Habitação (PNH), em 2004, com seus dois subsistemas, o de mercado e o de interesse social. Entre os objetivos da PNH, encontram-se: (i) a universalização do acesso à moradia digna; (ii) a promoção da urbanização, da regularização e da inserção de assentamentos precários; (iii) o fortalecimento do papel do Estado na política habitacional; (iv) a priorização nacional da questão habitacional; (v) a democratização do acesso à terra urbanizada; (vi) a ampliação da produtividade e a melhoria da qualidade na produção habitacional; e (vii) o incentivo à geração de emprego e renda, apoiando-se na indústria da construção civil.

Os desafios impostos a essa política eram significativos, fato comprovado pelos estudos sobre o déficit habitacional no Brasil, que estimaram em 5.546.310 habitações para o ano de 2008 (Brasil, 2011), composto, majoritariamente, de famílias com rendimento médio mensal de até três salários mínimos (Brasil, 2010). Para atuação com esse grupo populacional em situação de maior vulnerabilidade financeira, foi instituída, no âmago da PNH, a Política Nacional de Habitação de Interesse Social (PNHIS).

Ancorado nesse amplo e complexo desafio, questiona-se: quais contribuições podem ser feitas à PNHIS a partir da análise das etapas do ciclo de políticas públicas (policy cycle)? No intuito de identificar essas propostas, fundamentou-se na percepção dos gestores municipais de habitação, agentes da implementação dessa política que, pela sua proximidade com a população, possuem, em tese, profundo conhecimento quanto ao problema habitacional.

Inserir tais atores no contexto dessa política é relevante, visto que o distanciamento entre formuladores de políticas públicas e implementadores é uma realidade no Brasil (Arretche \& Marques, 2007), fato que pode prejudicar o desenvolvimento e a efetividade das ações governamentais. A partir deste artigo, analisou-se a PNHIS, em meio às etapas do ciclo de políticas públicas, no intuito de verificar os aspectos positivos e as possíveis falhas, sob a percepção dos gestores municipais. Ressalta-se que o estudo foi realizado entre os anos de 2011 e 2012, período em que a questão habitacional se manteve na agenda governamental. 


\section{Referencial teórico}

\section{Políticas públicas}

Em meio a um conjunto populacional robusto e heterogêneo, tem-se o advento de interesses, valores e aspirações de grupos, que podem expressar posições divergentes e estabelecer situações de enfrentamento. Como forma de manter os conflitos gerados em níveis aceitáveis, faz-se necessária a política (Rua, 1997). Quando estabelecida para o enfrentamento de um problema que afeta a coletividade, denota-se uma política pública, que representa uma orientação à atividade ou uma passividade de alguém (Secchi, 2010).

As políticas públicas são uma combinação entre planejamento racional, incrementalismo, concorrência entre grupos, preferências da elite, forças sistemáticas, processos políticos e influências institucionais (Dye, 2008). 0 fato de serem compostas dessa complexa rede de elementos impossibilita a formulação de uma definição singular quanto às políticas públicas, porém determinados fatores são reiterados por alguns estudiosos.

Diversos autores conceituaram as políticas públicas (Cunha \& Cunha, 2002; Saravia, 2006; Souza, 2006; Dye, 2008; Matias-Pereira, 2007; Smith \& Larimer, 2009), sendo possível destacar alguns elementos comuns entre suas concepções, como: a existência de um problema público; a resolução dos conflitos de forma pacífica; a presença de atores diversos; a existência de procedimentos formais e informais; e o estabelecimento de objetivos e estratégias de ação.

Declaradas de forma explícita ou não, as políticas implicam uma cadeia de causalidade, considerando as condições atuais e as consequências futuras (Rist, 1994). A presença de um problema de caráter público e sua consequente resolução pacífica representam a gênese para formação das políticas públicas.

Nesse sentido, Burger (1993), baseando-se em Jenkins (1978), ressalta que, por meio de um conjunto de decisões inter-relacionadas tomadas por um ator político ou por um agrupamento deles, são estipulados objetivos e os meios para alcançá-los. 0 autor destaca que esse agregado de decisões deve estar compreendido nos limites da alçada desses atores políticos.

Esse conjunto de decisões é entendido por Rist (1994) como orientações reunidas para serem transmitidas a implementadores. Tal passagem permite considerar a necessidade da interlocução entre os atores governamentais, demandando canais que permitam a correta e coerente transmissão de informações e/ou orientações.

Ao compreender a política pública enquanto área de conhecimento, é relevante apresentar a origem da teorização sobre esse campo. Conforme Souza (2006), essa teorização se deve às contribuições de Laswell, Simon, Lindblom e Easton, que, ao longo dos anos, desenvolveram conceitos importantes, conforme apresentado no Quadro 1.

Quadro 1 - Contribuições na área de políticas públicas

\begin{tabular}{|c|c|}
\hline Autores & Contribuiçōes \\
\hline Laswell (1936) & $\begin{array}{l}\text { Introduziu a expressão policy analysis (análise de política pública) como forma de conciliar o } \\
\text { conhecimento científico/acadêmico com a produção empírica dos governos e também como } \\
\text { forma de estabelecer o diálogo entre cientistas sociais, grupos de interesse e governo. }\end{array}$ \\
\hline Simon (1957) & $\begin{array}{l}\text { Introduziu o conceito de policy maker (racionalidade limitada dos decisores públicos). } \\
\text { Argumentou que a limitação da racionalidade poderia ser minimizada pelo conhecimento } \\
\text { racional e maximizada até um ponto satisfatório pela criação de estruturas (conjunto de regras e } \\
\text { incentivos) que enquadrem o comportamento dos atores e modelem esse comportamento na } \\
\text { direção de resultados desejados, sem, contudo, levar à maximização de interesses próprios. }\end{array}$ \\
\hline $\begin{array}{l}\text { Lindblom } \\
(1959,1979)\end{array}$ & $\begin{array}{l}\text { Questionou a ênfase no racionalismo de Laswell e Simon. O autor propôs a incorporação de } \\
\text { outras variáveis à formulação e análise de políticas públicas, tais como as relações de poder e a } \\
\text { integração entre as diferentes fases do processo decisório. }\end{array}$ \\
\hline Easton (1965) & $\begin{array}{l}\text { Definiu política pública como um sistema, estabelecendo uma relação entre formulação, } \\
\text { resultados e ambiente, em que as políticas públicas recebem inputs dos partidos, da mídia e dos } \\
\text { grupos de interesse, que influenciam seus resultados e efeitos. }\end{array}$ \\
\hline
\end{tabular}

Fonte: Retirado de Drumond et al. (2014) a partir de Souza (2006). 
Esse resgate conceitual contribui para o entendimento do surgimento dos modelos do ciclo de políticas públicas (policy cycle). Laswell, em 1956, foi o primeiro a modelar o processo político em estágios. A partir de sua modelagem, surgiram diferentes versões de tipologia de estágio.

\section{Ciclo de políticas públicas}

O ciclo de políticas públicas compreende a política pública a partir de vários estágios, os quais constituem um processo dinâmico de aprendizado (Souza, 2006). A distinção entre esses estágios é importante, uma vez que, em cada etapa, os atores, os processos e as ênfases são diferentes, possibilitando a compreensão dessas relações em cada um deles (Saravia, 2006).

Conforme Jann \& Wegrich (2007), a tipologia de estágios apresenta um forte apelo como modelo normativo e racional, o que contribuiu para o sucesso e a longevidade de sua utilização. Nesse mesmo sentido, Secchi (2010) argumenta que o ciclo de políticas públicas permite a organização da vida de uma política a partir do estabelecimento de fases sequenciais e interdependentes.

Para a análise proposta neste artigo, é adotado o ciclo de políticas públicas a partir das fases elaboradas por Frey (2000), as quais apresentam certo grau de similaridade com Theodoulou (1995): percepção e definição de problemas; agenda-setting (definição de agenda); elaboração de programas e decisão; implementação de políticas; e avaliação de políticas, com a eventual correção das ações. A Figura 1 representa esquematicamente a sequência das fases adotadas como constituintes do ciclo de políticas públicas.

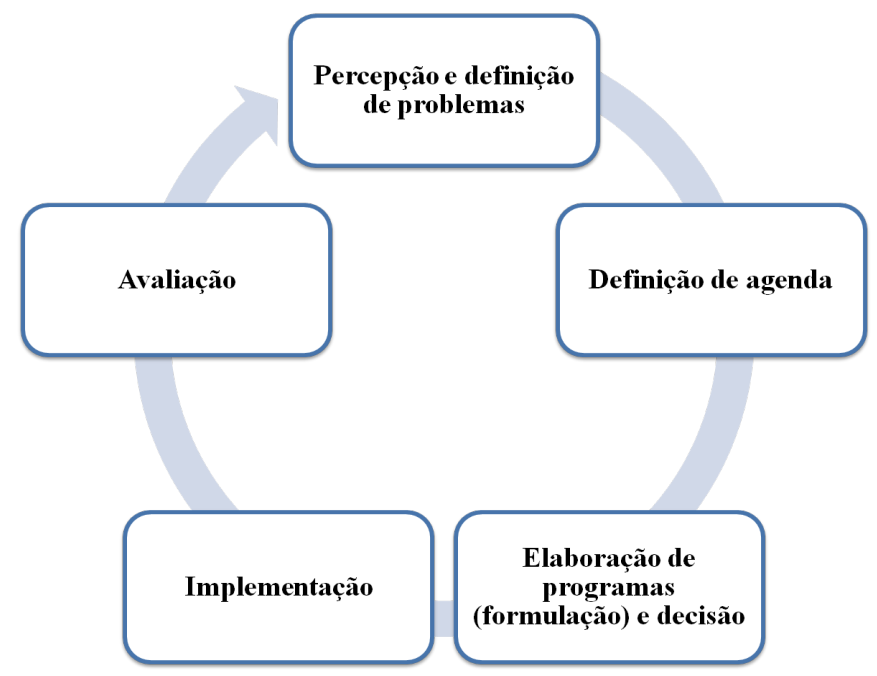

Figura 1 - Fases do ciclo de políticas públicas. Fonte: Elaborada por Silva (2011), a partir de Frey (2000).

A fase inicial caracteriza-se pela identificação, dentre os inúmeros problemas, daqueles mais apropriados para tratamento por meio de políticas públicas, podendo ser identificados por grupos sociais isolados, por grupos políticos ou pela administração pública (Frey, 2000).

Os problemas existentes, mesmo que reconhecidos, podem receber tratamento diferenciado por parte do Estado; assim, um problema público pode aparecer subitamente, como as catástrofes naturais; aos poucos, pode ganhar relevância, como o congestionamento das cidades; ou ainda, pode, por muito tempo, não receber a devida atenção, como a favelização das periferias das grandes cidades (Secchi, 2010).

A agenda governamental representa os problemas e os temas que são percebidos como prioridades e que são escolhidos como foco de ação dos agentes governamentais (Theodoulou, 1995). Conforme Rua (1997), a inclusão de determinado problema na agenda governamental decorre do atendimento de pelo menos um dos seguintes fatores: a) mobilização política de grandes grupos, de pequenos grupos dotados de poder ou da ação de indivíduos estrategicamente posicionados; b) constituição de uma calamidade ou 
catástrofe, em que o ônus de não resolver o problema é maior que o ônus de resolvê-lo; c) seja uma oportunidade, para que, por meio de sua solução, obtenham-se vantagens.

A fase de formulação de políticas públicas tem como propósito elaborar políticas, programas e projetos considerados consistentes e capazes de promover soluções aos temas que compõem a agenda de governo. Segundo Jann \& Wegrich (2007), durante a formulação de políticas públicas, problemas, propostas e demandas são transformados em programas de governo.

A etapa de implementação abrange todo o conjunto de decisões e ações que devem ser realizadas pelos agentes ou pelas instituições governamentais e por demais grupos ou indivíduos, de natureza privada, para que a política formulada e seus objetivos sejam alcançados, ou seja, trata-se das ações para que determinada política saia do papel (Rua, 1997).

Conforme Jann \& Wegrich (2007) ressaltam, na fase de execução da política as instituições e as organizações responsáveis por sua implantação exercem grande influência nos processos de implementação e, por consequência, nos seus resultados. Os autores recordam que a execução nem sempre é de exclusiva responsabilidade do Estado, sendo necessária a utilização de mecanismos para avaliação.

A fase de avaliação é importante, pois permite a compreensão do Estado em ação e a geração de informações, como subsídio à tomada de decisão. A partir dos resultados da avaliação, pode-se propor modificações ao programa, suspensão ou até mesmo exclusão dele, encerrando-se um ciclo de políticas públicas. Rua (1997) ressalta que o controle ou a avaliação não devem ser realizados somente ao final da implementação, mas sim podem estar presentes durante todas as fases do ciclo de políticas públicas. Assim, a avaliação ocorre em dois níveis diferentes: a avaliação de processo, que analisa a forma como os recursos foram utilizados e os processos que favorecem e dificultam a implementação da política; e a avaliação de resultados, que visa identificar o desempenho, o impacto e os efeitos da política (Draibe, 2001).

\section{Política Nacional de Habitação de Interesse Social (PNHIS)}

A habitação é uma demanda antiga no Brasil. Ao reportar a um período mais recente de análise, tem-se, como expressão dessa demanda, a elaboração do Projeto de lei no 2.710/1992, de iniciativa popular, que reivindicava a criação de um fundo nacional de moradia popular como meio de subsidiar os investimentos necessários para o acesso a moradias. Somente em 2003, com a criação do Ministério das Cidades, e em 2004, com a elaboração da PNH, que o Governo Federal passou a incorporar a questão habitacional na agenda de governo.

0 referido Projeto de lei (no 2.710/1992) somente alcançou um resultado prático em 2005, quando foi aprovada a Lei no 11.124, que dispunha sobre o Sistema Nacional de Habitação de Interesse Social (SNHIS), criava o Fundo Nacional de Habitação de Interesse Social (FNHIS) e instituía o Conselho Gestor do FNHIS.

O SNHIS objetiva proporcionar o acesso da população de menor renda à terra urbanizada e à habitação digna e sustentável; implementar políticas e programas de investimento e subsídios destinados à população de menor renda; articular, compatibilizar e apoiar a atuação de órgãos de interesse social que desempenham funções no setor de habitação (Brasil, 2004).

O Ministério das Cidades apresenta-se como órgão central do SNHIS, que é também composto de um Conselho Gestor do FNHIS, da Caixa Econômica Federal (CAIXA) como agente operador, do Conselho das Cidades, dos Conselhos Estaduais e Municipais, cujas especificidades sejam relativas a questões urbanas e habitacionais, e de entidades, órgãos e instituições da administração pública direta e indireta e da sociedade civil que atuam na área de habitação.

O Conselho Gestor do FNHIS tem por atribuições estabelecer diretrizes e critérios de alocação dos recursos, aprovar orçamentos, planos de aplicação e metas anuais e plurianuais e deliberar sobre as contas do FNHIS. A CAIXA, enquanto agente operador do FNHIS, tem por competências atuar como instituição depositária dos recursos do FNHIS, definir e implementar os procedimentos operacionais 
necessários à aplicação dos recursos, controlar a execução físico-financeira e prestar contas ao Ministério das Cidades.

Os Conselhos Estaduais, Municipais e do Distrito Federal são considerados integrantes do SNHIS e apresentam atribuições específicas. 0 estabelecimento de critérios para a priorização das linhas de ação, para a alocação de recursos e para o atendimento dos beneficiários dos programas habitacionais fica a cargo dos Conselhos, que devem dar ampla publicidade às regras e aos acessos.

O SNHIS utiliza recursos do FNHIS, o qual é mantido pelo Orçamento Geral da União (OGU). Entretanto, existem outros fundos que são utilizados para o financiamento de programas habitacionais: o Fundo de Amparo ao Trabalhador (FAT), o Fundo de Garantia do Tempo de Serviço (FGTS) e o Fundo Desenvolvimento Social (FDS).

De acordo com os princípios da integração entre entes federados, a descentralização e a transparência do SNHIS, os municípios e os Estados devem constituir fundos e conselhos para implementar a PNHIS e receber os recursos do FNHIS, elaborar Plano Diretor e Plano Local de Habitação de Interesse Social que contemplem a utilização de tais recursos por meio da política de desenvolvimento urbano, firmar termo de adesão ao sistema e elaborar relatórios de gestão (Brasil, 2004).

A exigência desses procedimentos colabora para o acompanhamento pela sociedade da utilização dos recursos dos fundos por intermédio dos Conselhos Municipais e Estaduais de Habitação, para a constituição político-administrativa municipal mais planejada, organizada, consistente, responsável e transparente.

A utilização dos recursos do FNHIS está condicionada à contrapartida por parte dos Estados ou municípios, cujas condições são estabelecidas pelo Conselho Gestor do FNHIS. Entidades privadas sem fins lucrativos, que têm objetivos em consonância com os fundos, podem receber recursos do FNHIS para executar projetos relacionados à habitação de interesse social. Esse processo de repasse é constituído por meio de chamadas públicas às entidades e exige que o objeto social da entidade seja compatível com o projeto a ser implementado, bem como apresente funcionamento regular por no mínimo três anos.

Com o objetivo de esclarecer o modo como a PNH tem se traduzido em ações, foram apresentados os treze programas federais voltados à habitação de interesse social, indicando o perfil das famílias beneficiárias, as modalidades de ação e o período de execução desses programas em municípios do Estado de Minas Gerais (Quadro 2).

Quadro 2 - Programas da PNHIS conforme as famílias beneficiárias, as modalidades de atendimento e o período de execução em Minas Gerais

\begin{tabular}{|c|l|c|}
\hline Programas federais & \multicolumn{1}{|c|}{ Modalidades } & $\begin{array}{c}\text { Período de } \\
\text { execução em } \\
\text { Minas Gerais }\end{array}$ \\
\hline (HIS) Lotes & $\begin{array}{l}\text { Projeto do empreendimento, legalização do terreno, } \\
\text { equipamentos comunitários e pagamento de custo de } \\
\text { construção em mutirão. }\end{array}$ & 2006 e 2008 \\
\hline (HIS) Assistência Técnica & $\begin{array}{l}\text { Melhoria dos padrões de salubridade, segurança e } \\
\text { habitabilidade por meio de prestação de serviços de } \\
\text { assistência técnica. }\end{array}$ & 2007 e 2008 \\
\hline $\begin{array}{c}\text { (HIS) Elaboração de Planos Locais } \\
\text { de Habitação de Interesse Social }\end{array}$ & $\begin{array}{l}\text { Contribuição com os Estados e os municípios na } \\
\text { formulação dos Planos Locais de Habitação. }\end{array}$ & 2007 a 2010 \\
\hline $\begin{array}{c}\text { Ação de Apoio à Produção Social } \\
\text { de Moradia }\end{array}$ & $\begin{array}{l}\text { Apoio a entidades privadas sem fins lucrativos do setor } \\
\text { habitacional no acesso à moradia digna para famílias } \\
\text { de baixa renda. }\end{array}$ & 2008 \\
\hline (HIS) Produção Habitacional & $\begin{array}{l}\text { Apoio a intervençães necessárias à construção ou à } \\
\text { aquisição de unidades habitacionais em áreas } \\
\text { legalmente estabelecidas. }\end{array}$ & 2006 a 2009 \\
\hline $\begin{array}{l}\text { Urbanização, Regularização e } \\
\text { Integração de Assentamentos } \\
\text { Precários }\end{array}$ & $\begin{array}{l}\text { Intervenções de regularização fundiária, segurança, } \\
\text { salubridade e habitabilidade em área inadequada ou } \\
\text { em situação de risco. }\end{array}$ & 2006 a 2009 \\
\hline Carta de Crédito Individual & $\begin{array}{l}\text { Aquisição, construção, conclusão, ampliação, reforma } \\
\text { ou melhoria da habitação, aquisição de material de } \\
\text { construção ou de lote urbanizado. }\end{array}$ & 2003 a 2010 \\
\hline
\end{tabular}


Quadro 2 - Continuação...

\begin{tabular}{|c|l|c|}
\hline Programas federais & \multicolumn{1}{|c|}{ Modalidades } & $\begin{array}{c}\text { Período de } \\
\text { execução em } \\
\text { Minas Gerais }\end{array}$ \\
\hline Carta de Crédito Associativo & $\begin{array}{l}\text { Concessão de financiamento habitacional para } \\
\text { pessoas físicas associadas a grupos de condomínios, } \\
\text { sindicatos, cooperativas, associações ou empresas de } \\
\text { construção civil. }\end{array}$ & 2003 a 2010 \\
\hline Pró-Moradia & $\begin{array}{l}\text { Urbanização de assentamentos precários, produção de } \\
\text { conjuntos habitacionais e desenvolvimento institucional. }\end{array}$ & 2007 a 2009 \\
\hline Projetos Multissetoriais Integrados & $\begin{array}{l}\text { Permitir o acesso à infraestrutura urbana, moradia } \\
\text { adequada e serviços básicos para população em } \\
\text { vulnerabilidade social. }\end{array}$ & 2007 e 2010 \\
\hline Prbanos (PMI) & $\begin{array}{l}\text { Financiamento habitacional a famílias organizadas em } \\
\text { cooperativas, associações, sindicatos ou entidades da } \\
\text { sociedade civil. }\end{array}$ & 2006 a 2008 \\
\hline $\begin{array}{c}\text { Programa de Arrendamento } \\
\text { Residencial (PAR) }\end{array}$ & $\begin{array}{l}\text { Arrendamento residencial com a opção de compra } \\
\text { com o objetivo de ampliar o acesso à moradia para a } \\
\text { população de baixa renda. }\end{array}$ & 2003 a 2010 \\
(exceto 2008)
\end{tabular}

Fonte: Elaboração própria a partir de informações do sítio eletrônico do Ministério das Cidades (Brasil, 2012).

\section{Metodologia}

Esta pesquisa caracteriza-se como descritiva, pois visa analisar a PNHIS a partir da percepção dos gestores públicos municipais, o que permite uma avaliação do desenvolvimento dessa política.

Para tanto, foi elaborado um questionário com temas referentes: à situação habitacional do país, às características dos programas que compõem a PNHIS, aos investimentos realizados e seus resultados, bem como aos treinamentos oferecidos aos gestores municipais envolvidos diretamente com os programas habitacionais implementados em Minas Gerais.

O universo de análise foi composto de municípios mineiros que possuíam, já no ano 2000, uma população superior a 20 mil habitantes. Após identificação prévia dos responsáveis pela pasta de habitação, realizou-se a aplicação do questionário, que foi conduzida por três métodos de coleta: via on-line, meio impresso enviado pelos Correios e aplicação direta com visita in loco. A coleta de dados foi iniciada no mês de agosto de 2011 e concluída no mês de janeiro de 2012. Deve ser evidenciado que houve a aplicação, in loco, de três questionários em caráter de pré-teste visando alinhar o instrumento de coleta em termos de compreensão dos questionamentos pelos gestores.

As visitas in loco visaram promover o maior aprofundamento dos conhecimentos dos pesquisadores com o objeto de investigação, em busca de compreender o desenvolvimento dos programas habitacionais nas diversas regiões do Estado de Minas Gerais. Na Tabela 1, apresenta-se a distribuição da participação dos gestores municipais pelo método de coleta utilizado.

Tabela 1 - Distribuição dos gestores municipais pelo método de coleta dados

\begin{tabular}{ccc}
\hline Métodos de coleta & Quantidade de gestores & Proporção dos gestores \\
\hline Questionário on-line & 37 & $62,71 \%$ \\
Aplicação direta (visita in loco) & 14 & $23,73 \%$ \\
Impresso (por correio) & 8 & $13,56 \%$ \\
Total de gestores participantes & 59 & $100,00 \%$ \\
\hline
\end{tabular}

Fonte: Elaboração própria. 
Obteve-se a participação de 59 gestores municipais, de todas as regiões administrativas do Estado de Minas Gerais. Essa representatividade foi importante, pois permitiu vislumbrar a percepção de gestores que atuavam sob influência de ambientes sociais e econômicos distintos entre si. Na Tabela 2, é apresentada a distribuição dos gestores participantes, de acordo com as regiões administrativas do Estado.

Tabela 2 - Distribuição dos gestores participantes por região administrativa de Minas Gerais

\begin{tabular}{cccc}
\hline $\begin{array}{c}\text { Região } \\
\text { administrativa }\end{array}$ & $\begin{array}{c}\text { Quantidade de } \\
\text { gestores participantes }\end{array}$ & $\begin{array}{c}\text { Proporção dos } \\
\text { gestores participantes }\end{array}$ & $\begin{array}{c}\text { Distribuição de } \\
\text { todos os } \\
\text { municípios de } \\
\text { Minas Gerais }\end{array}$ \\
\hline Alto Paranaíba & 4 & $6,78 \%$ & $3,63 \%$ \\
Central & 21 & $35,59 \%$ & $18,41 \%$ \\
Centro-Oeste & 7 & $11,86 \%$ & $6,57 \%$ \\
Jequitinhonha-Mucuri & 2 & $3,39 \%$ & $7,74 \%$ \\
Mata & 6 & $10,17 \%$ & $16,76 \%$ \\
Noroeste & 1 & $1,69 \%$ & $2,11 \%$ \\
Norte & 2 & $3,39 \%$ & $10,55 \%$ \\
Rio Doce & 4 & $6,78 \%$ & $11,96 \%$ \\
Sul de Minas & 9 & $15,25 \%$ & $18,17 \%$ \\
Triângulo & 3 & $5,08 \%$ & 4,10 \\
Total & 59 & $100,00 \%$ & $100,00 \%$ \\
\hline
\end{tabular}

Fonte: Elaboração própria.

O questionário foi construído predominantemente a partir da escala Likert, em que se busca identificar o grau de concordância dos respondentes em relação a cada questão apresentada pelo pesquisador. As questões de interesse foram elaboradas a partir de frases afirmativas ou negativas, e não em forma de perguntas.

Tais questões apresentaram cinco opções de resposta: Discordo totalmente, Discordo parcialmente, Nem discordo e nem concordo, Concordo parcialmente e Concordo totalmente. Para analisar cada uma das questões, conforme o grau de concordância dos respondentes, adotou-se o seguinte procedimento:

1. Atribuíram-se "pesos" para cada resposta (Quadro 3).

Quadro 3 - Pesos atribuídos às opções de resposta

\begin{tabular}{|c|c|c|c|c|c|}
\hline Alternativas & $\begin{array}{c}\text { Discordo } \\
\text { totalmente }\end{array}$ & $\begin{array}{c}\text { Discordo } \\
\text { parcialmente }\end{array}$ & $\begin{array}{c}\text { Nem discordo e } \\
\text { nem concordo }\end{array}$ & $\begin{array}{c}\text { Concordo } \\
\text { parcialmente }\end{array}$ & $\begin{array}{c}\text { Concordo } \\
\text { totalmente }\end{array}$ \\
\hline $\begin{array}{c}\text { Pesos } \\
\text { atribuídos }\end{array}$ & -2 & -1 & 0 & 1 & 2 \\
\hline
\end{tabular}

Fonte: Elaboração própria.

2. Calcularam-se, conforme o número de respondentes, o menor e o maior valor possível. Dessa forma, como eram 59 respondentes, houve o menor valor possível em -118 e o maior valor possível em +118 .

3. A partir da distância entre o menor e o maior valor, foram estipulados cinco graus de concordância, os quais eram equidistantes. Os cinco graus de concordância, conforme seus limites superiores, são apresentados no Quadro 4.

Quadro 4 - Limites superiores de pontuação para cada grau de concordância

\begin{tabular}{|c|c|c|c|c|}
\hline \multicolumn{5}{|c|}{ Graus de concordância } \\
\hline Muito baixo & Baixo & Médio & Alto & Muito alto \\
\hline$-70,8$ & $-23,6$ & 23,6 & 70,8 & 118 \\
\hline
\end{tabular}

Fonte: Elaboração própria.

A partir dos graus de concordância obtidos em cada questão de pesquisa, foram tecidas as análises sobre cada etapa do ciclo política da PNHIS. Deve ser ressaltado que, em determinados questionamentos 
pontuais, outras configurações de escala foram utilizadas na análise dos resultados. Visando demonstrar a percepção de "qualidade" de determinados elementos, dispôs-se de uma variação entre: Péssima, Ruim, Boa, Muito boa e Ótima.

Cada questão foi respaldada a partir das etapas do policy cycle, cujas premissas básicas foram abordadas no tópico "Referencial Teórico". Com base na percepção dos gestores municipais, buscou-se compreender de que maneira o tema habitação era vislumbrado pelo poder público como um problema de ordem social e sua relevância na agenda governamental. Em termos de atuação dos entes públicos, procurou-se analisar as alternativas, em termos de políticas e programas, disponíveis para enfrentamento do problema, assim como seus processos de implementação. E, por fim, verificaram-se a existência e a efetividade de instrumentos para avaliar os efeitos e os impactos das ações públicas.

\section{Resultados e discussão}

\section{Percepção de problemas e definição de agenda}

Com o intuito de verificar a percepção dos gestores em relação à questão habitacional como um problema social, como elegível à agenda dos governos e como ela deveria ser tratada a partir de uma política pública, foram realizadas quatro questões. Ao serem questionados sobre a situação habitacional no país, 57,63\% dos gestores apresentaram uma percepção negativa (Ruim ou Péssima), e 42,37\% dos participantes tiveram uma percepção positiva (Boa, Muito boa e Ótima) (Tabela 3).

Tabela 3 - Distribuição dos respondentes entre as alternativas sobre a atual situação habitacional do país

\begin{tabular}{cccccc}
\hline $\begin{array}{c}\text { Posicionamento dos } \\
\text { gestores }\end{array}$ & Péssima & Ruim & Boa & Muito boa & Ótima \\
\hline $\begin{array}{c}\text { Quantidade } \\
\text { Proporção }\end{array}$ & 5 & 29 & 22 & 2 & 1 \\
\hline
\end{tabular}

Fonte: Elaboração própria.

Uma vez percebida a situação habitacional do país ainda como incipiente, carente de melhorias, questionou-se quanto à intervenção do Estado nessa área, como provedor de soluções e investimentos. Entre todos os gestores participantes, a resposta foi unânime: os governos deveriam investir recursos públicos para melhorar a situação habitacional do país. Conforme ilustrado na Tabela 4, para a grande maioria dos gestores $(93,22 \%)$ a questão habitacional deveria ser tratada entre as três primeiras prioridades de um governo, sendo que nenhum apontou a temática como não prioritária.

Tabela 4 - Ordem de prioridade do investimento público em habitação, segundo uma escala de ações prioritárias de governo

\begin{tabular}{ccccccc}
\hline $\begin{array}{c}\text { Posicionamento dos } \\
\text { gestores }\end{array}$ & $\mathbf{1}^{\circ}$ lugar & $\mathbf{2}^{\circ}$ lugar & $\mathbf{3}^{\circ}$ lugar & $\mathbf{4}^{\circ}$ lugar & $\mathbf{5}^{\circ}$ lugar & Não é prioridade \\
\hline Quantidade & 8 & 20 & 27 & 4 & 0 & 0 \\
Proporção & $13,56 \%$ & $33,90 \%$ & $45,76 \%$ & $6,78 \%$ & $0,00 \%$ & $0,00 \%$ \\
\hline
\end{tabular}

Fonte: Elaboração própria.

A respeito dos investimentos em habitação, 66,10\% dos gestores apontaram que o direcionamento dessa política deveria focalizar famílias com rendimento médio mensal de até três salários mínimos. Desse total, 15,25\% destacaram que os investimentos deveriam focalizar famílias com até um salário mínimo (Tabela 5). 
Tabela 5 - Faixas de renda familiar para as quais os investimentos em habitação deveriam ser focalizados

\begin{tabular}{cccccc}
\hline $\begin{array}{c}\text { Posicionamento } \\
\text { dos gestores }\end{array}$ & $\begin{array}{c}\text { Até 1 salário } \\
\text { mínimo }\end{array}$ & $\begin{array}{c}\text { Até 3 salários } \\
\text { mínimos }\end{array}$ & $\begin{array}{c}\text { Até } 5 \text { salários } \\
\text { mínimos }\end{array}$ & $\begin{array}{c}\text { Até } 10 \text { salários } \\
\text { mínimos }\end{array}$ & $\begin{array}{c}\text { Para todas as } \\
\text { faixas }\end{array}$ \\
\hline $\begin{array}{c}\text { Quantidade } \\
\text { Proporção }\end{array}$ & 9 & 30 & 9 & 3 & 7 \\
\hline
\end{tabular}

Fonte: Elaboração própria.

Ressalta-se que, entre os gestores que responderam que tal política deveria atender a famílias de até dez salários mínimos ou todas as faixas de rendimento (16,95\%), alguns apresentaram em suas falas que deveria ser elaborada uma política atendendo prioritariamente às famílias com rendimento médio mensal inferior, posteriormente oferecendo apoio às famílias que possuíssem uma renda mais elevada.

A partir dos estudos sobre o déficit habitacional no Brasil, no ano 2008 a estimativa alcançava 5.572.313 habitações, das quais $89,6 \%$ eram compostas de famílias de rendimento médio mensal de até três salários mínimos. No mesmo ano, em Minas Gerais, o déficit habitacional foi de 476.287 moradias, e as famílias com até três salários mínimos correspondiam a 92,5\% desse déficit total (Brasil, 2010).

Percebe-se um compartilhamento de ideias entre os gestores municipais e a Lei no 11.124 de 2005, que criou o SNHIS, ao objetivar o acesso à terra urbanizada e à moradia digna por meio de políticas e programas de investimento e subsídios direcionados à população de menor renda.

Com essas ações, o Governo Federal incorpora a demanda social por moradia como uma questão presente na agenda do governo. Entende-se que o fator que motivou a inserção dessa temática na agenda governamental adveio da mobilização política e de grupos da sociedade (Rua, 1997), como os movimentos sociais por moradia.

Assim, a questão habitacional tornou-se reconhecida como merecedora de intervenção por diferentes atores. 0 Governo Federal encarou essa questão como necessária e factível e que se encaixava na própria concepção de responsabilidades públicas desse governo que iniciava, no ano de 2003, o seu primeiro mandato. Nesse contexto, foi elaborada a PNH e seus respectivos programas habitacionais.

\section{Elaboração de programas}

No mesmo ano de instituição do Ministério das Cidades, foram realizadas as conferências municipais, regionais e nacional das cidades, a partir das quais foi criado o Conselho Nacional das Cidades e foram eleitos os seus representantes. Esse Conselho é constituído por quatro Comitês Técnicos: Habitação, Planejamento Territorial Urbano, Saneamento Ambiental, e Transporte e Mobilidade Urbana.

A PNH foi criada em 2004 em decorrência desse processo pelo Conselho Nacional das Cidades, com especial apoio do Comitê Técnico de Habitação. Destaca-se nessa política o estabelecimento de sete objetivos, dos quais se destacam: universalizar o acesso à moradia digna, promover a urbanização, a regularização e a inserção de assentamentos precários, fortalecer o papel do Estado na política habitacional, instituir a habitação como prioridade nacional e democratizar o acesso à terra urbanizada.

Os resultados do estudo apontam para um alto grau de concordância dos gestores municipais quanto à focalização dos investimentos da PNH e, por consequência, de seus programas em famílias de mais baixa renda. Outro aspecto de relevância para análise da elaboração dos programas se refere às propostas de enfrentamento do déficit habitacional. Nesse quesito, os gestores municipais se posicionaram com alto grau de concordância, considerando que os programas implementados constituíam ótimas propostas (Quadro 5). 
Quadro 5 - Questões, índice e grau de concordância sobre a elaboração dos programas

\begin{tabular}{|c|l|c|c|}
\hline Questão & \multicolumn{1}{|c|}{ Elaboração dos programas } & Índice & $\begin{array}{c}\text { Grau de } \\
\text { concordância }\end{array}$ \\
\hline 5 & $\begin{array}{l}\text { Os investimentos destinados às famílias de mais baixa renda (habitação } \\
\text { de interesse social) representavam o foco da PNH. }\end{array}$ & 44 & Alto \\
\hline 6 & $\begin{array}{l}\text { Os programas implementados eram uma ótima proposta de } \\
\text { enfrentamento do déficit habitacional. }\end{array}$ & 43 & Alto \\
\hline 7 & $\begin{array}{l}\text { A diversidade dos programas não contemplava a diversidade das } \\
\text { necessidades. }\end{array}$ & 7 & Médio \\
\hline 8 & $\begin{array}{l}\text { As especificidades locais eram consideradas na execução dos } \\
\text { programas. }\end{array}$ & -14 & Baixo \\
\hline 9 & $\begin{array}{l}\text { Onúmero de cômodos das moradias construídas atendia às demandas } \\
\text { das famílias beneficiadas. }\end{array}$ \\
\hline
\end{tabular}

Fonte: Elaboração própria.

Um questionamento que se faz, partindo do pressuposto de que as famílias possuem diversas necessidades, é se os programas elaborados, cada qual com sua proposta e modalidade de atendimento, eram suficientes para atender à diversidade das necessidades das famílias. Ao refletirem sobre esse aspecto, a opinião dos gestores municipais foi diversa, resultando em um grau médio de concordância. Os gestores foram mais céticos ao analisarem o fato de as especificidades locais serem consideradas na execução dos programas.

Em relação ao número de cômodos das moradias construídas, houve um baixo grau de concordância, representado pela opinião de $71,19 \%$ dos respondentes. Esse resultado justifica-se pelo fato de as famílias atendidas apresentarem uma composição familiar numerosa e os programas habitacionais seguirem um padrão de construção normalmente fixado em dois quartos, sala, cozinha, banheiro e uma área de serviço, não atendendo às necessidades de espaço da família. As questões discutidas como etapa de elaboração dialogam com a execução dos empreendimentos habitacionais; sendo assim, prossegue-se a análise da implementação.

\section{Implementação}

Ao reconhecer que há a possibilidade de restrição orçamentária, perguntou-se aos gestores municipais se os investimentos realizados pela PNH entre os anos de 2004 a 2010 foram inferiores ao nível adequado para o período. 0 resultado obtido foi um alto grau de concordância, ou seja, deveria ter sido feito um esforço maior para alocação dos recursos públicos na questão habitacional. Entretanto, a realização desta pesquisa evidencia outro fator que se apresenta, na percepção dos gestores municipais de habitação, com maior ênfase: o excesso de burocracia e de dificuldades dos procedimentos para os municípios acessarem os programas da PNH, conforme demonstrado no Quadro 6.

Quadro 6 - Questões, índice e grau de concordância sobre a implementação da PNHIS

\begin{tabular}{|c|l|c|c|}
\hline Questão & \multicolumn{1}{|c|}{ Implementação } & Índice & $\begin{array}{c}\text { Grau de } \\
\text { concordância }\end{array}$ \\
\hline 10 & $\begin{array}{l}\text { Os investimentos realizados pela PNH desde 2004 até 2010 foram inferiores } \\
\text { ao adequado para o período. }\end{array}$ & 30 & Alto \\
\hline 11 & $\begin{array}{l}\text { Os procedimentos para os municípios acessarem os programas da PNH } \\
\text { apresentavam excesso de burocracia e dificuldades. }\end{array}$ & 42 & Alto \\
\hline 12 & $\begin{array}{l}\text { Os programas implementados no município apresentavam ótimos } \\
\text { resultados. }\end{array}$ & 20 & Médio \\
\hline 13 & $\begin{array}{l}\text { A qualidade (material, espaço, localização e equipamentos urbanos) das } \\
\text { habitações construídas era satisfatória. }\end{array}$ & 1 & Médio \\
\hline 14 & $\begin{array}{l}\text { A forma como o Governo Federal, o Estado de Minas Gerais e os municípios } \\
\text { estavam articulados favorecia a implementação dos programas da PNH. }\end{array}$ & -7 & Médio \\
\hline 15 & $\begin{array}{l}\text { Os investimentos dos programas da PNH foram adequadamente } \\
\text { distribuídos pelas regiões brasileiras em função do déficit habitacional. }\end{array}$ & -18 & Médio \\
\hline
\end{tabular}


Quadro 6 - Continuação...

\begin{tabular}{|c|l|c|c|}
\hline Questão & \multicolumn{1}{|c|}{ Implementação } & Índice & $\begin{array}{c}\text { Grau de } \\
\text { concordância }\end{array}$ \\
\hline 16 & $\begin{array}{l}\text { Os investimentos dos programas da PNH foram adequadamente } \\
\text { distribuídos entre os municípios de Minas Gerais em função do déficit } \\
\text { habitacional. }\end{array}$ & -20 & Médio \\
\hline 17 & $\begin{array}{l}\text { A qualidade das capacitações oferecidas aos servidores da área de } \\
\text { habitação era satisfatória. }\end{array}$ & -21 & Médio \\
\hline 18 & $\begin{array}{l}\text { A quantidade de cursos para capacitação de servidores municipais da } \\
\text { área de habitação era satisfatória. }\end{array}$ & -61 & Baixo \\
\hline
\end{tabular}

Fonte: Elaboração própria.

Independentemente das restrições presentes no âmbito da PNH, é necessário verificar se os programas implementados apresentavam resultados satisfatórios. Em relação a essa questão, a maioria dos gestores municipais de habitação (59,32\%) posicionou-se a favor de que os resultados eram ótimos. Ressalta-se que a obtenção do grau médio de concordância pode se dar pela força da expressão "ótimos resultados", uma vez que, entre os gestores entrevistados, foi recorrente a ponderação: "ótimos resultados não, mas sim bons resultados".

Com o intuito de melhor compreender os resultados da implementação dos programas, foi elaborada a questão sobre a qualidade das habitações construídas, no que diz respeito aos materiais utilizados, ao espaço, à localização e à presença de equipamentos urbanos no entorno. Nesse aspecto, os gestores apresentaram opiniões diversas e de modo equilibrado, o que dificultou estabelecer um posicionamento incisivo. Alguns aspectos contribuíram para esse resultado, pois a ideia de "qualidade satisfatória" é subjetiva, além de os diversos empreendimentos habitacionais poderem variar em termos de qualidade dentro de um mesmo município, quanto mais em municípios diferentes.

Entre as diretrizes da PNH, há orientações para a adequada articulação entre os entes federados (União, Estados e municípios) como forma de viabilizar os planos, os programas e as ações dessa política. Essa integração é fundamental para a destinação de recursos por meio dos fundos nacional, estaduais e municipais de habitação. Apesar da importância dessa relação entre os entes federados, a percepção dos gestores públicos municipais não foi positiva, uma vez que $47,46 \%$ dos respondentes discordaram que a forma como esses governos estavam articulados favorecia a implementação da PNH.

Na base da PNH, encontra-se a gestão democrática por meio das conferências realizadas no âmbito municipal, regional e nacional, da participação da sociedade civil e das organizações populares no Conselho das Cidades e no Conselho Gestor do Fundo Nacional de Habitação. Dessa forma, pressupõe-se que a distribuição dos investimentos tende à equidade conforme o diagnóstico de déficit habitacional nos Estados e municípios.

Com o intuito de investigar a veracidade dessa pressuposição, foi elaborada uma questão referente à distribuição equânime dos investimentos entre as regiões do país e outra entre os municípios de Minas Gerais em função do déficit habitacional. Os resultados dessas questões não foram satisfatórios, uma vez que, para ambas as questões, $45,76 \%$ dos gestores municipais discordaram que a distribuição dos recursos da PNH tivesse sido adequada. Ressalta-se que um considerável número de gestores $(23,73 \%)$ optou pela resposta "Nem discordo e nem concordo". Essa dificuldade em posicionar-se sugere que há pouco estudo produzido que demonstre a distribuição dos recursos em habitação comparando-a com a distribuição do déficit habitacional nos municípios brasileiros ou que há pouco acesso a esses estudos por parte dos gestores municipais de habitação de Minas Gerais.

Nesse sentido, investir na capacitação dos gestores municipais é relevante. Entretanto, ao investigar essa questão, encontram-se os dois resultados críticos: a qualidade das capacitações oferecidas não foi considerada satisfatória e, principalmente, a quantidade de cursos de capacitação para servidores municipais foi considerada insatisfatória.

Esse resultado colabora para a compreensão dos gestores municipais apontarem que os procedimentos para acesso aos programas da $\mathrm{PNH}$ apresentavam excesso de burocracia e dificuldades. Quanto menor o entendimento sobre determinado procedimento, mais complexo ele 
tende a ser, de modo que, com baixo número de capacitações oferecidas e ainda com a qualidade duvidosa, as dificuldades tendem a sobressair. A literatura aponta que esse problema pode afetar diretamente os resultados da política, visto que, de acordo com Jann \& Wegrich (2007), os agentes implementadores exercem grande influências nos processos de execução que, consequentemente, influenciam nos seus resultados.

\section{Monitoramento e avaliação}

Para realizar o monitoramento e a avaliação da política habitacional, o SNHIS estabeleceu a criação do Sistema de Informação, Monitoramento e Avaliação da Habitação (SIMAHAB), que prevê o desenvolvimento de uma base de informações, o monitoramento e a avaliação permanente dos projetos e programas da $\mathrm{PNH}$, de forma articulada aos demais aspectos da política de desenvolvimento urbano, entretanto o SIMAHAB ainda não apresenta sinais de que tenha sido implementado.

Como destacado por Draibe (2001), os resultados de uma política podem ser analisados de duas formas: por meio do processo e por seus resultados. Neste estudo, os questionamentos visaram abordar uma análise do processo, buscando melhor entendimento quanto à sua forma de realização e ao seu efetivo funcionamento.

O que pode ser inferido, a partir da opinião dos gestores municipais, é que tanto o Ministério das Cidades como a CAIXA exigiam das prefeituras relatórios e prestação de contas sobre os recursos destinados à implantação dos programas habitacionais. Essa exigência permitia o controle sobre a implementação dos empreendimentos - pré-requisito para a alimentação de um sistema de monitoramento e avaliação -, porém não assegurava que tal sistema de monitoramento estivesse em pleno funcionamento.

Outro aspecto relacionado ao monitoramento e à avaliação é a própria capacidade de a instituição ou o projeto serem analisados por terceiros, referindo-se à qualidade da transparência. Com grau médio de concordância, identificou-se que 55,93\% dos respondentes concordavam que havia transparência nos processos e nos resultados da $\mathrm{PNH}$, o que se apresenta como um resultado positivo. Entre as principais organizações que podem e devem fazer o acompanhamento da implementação da PNH, encontram-se os Conselhos Municipais de Habitação.

Os resultados, apesar de tímidos, apresentam aspecto positivo. Vale ressaltar que, na percepção dos gestores, as propostas resultantes da participação social eram incorporadas pela PNH. Identificou-se, em relação à Questão 21, que 55,93\% dos respondentes concordavam com essa afirmação. Em relação à PNH possuir, em nível satisfatório, espaço para a participação social, identificou-se que $54,24 \%$ dos gestores tinham uma percepção positiva e favorável a essa questão (Quadro 7).

Quadro 7 - Questões, índice e grau de concordância sobre o monitoramento e a avaliação

\begin{tabular}{|c|l|c|c|}
\hline Questão & \multicolumn{1}{|c|}{ Monitoramento e avaliação } & índice & $\begin{array}{c}\text { Grau de } \\
\text { concordância }\end{array}$ \\
\hline 19 & $\begin{array}{l}\text { O Ministério das Cidades e a CAIXA exigiam da prefeitura relatórios e } \\
\text { prestação de contas sobre os recursos destinados à implantação dos } \\
\text { programas de habitação. }\end{array}$ & 77 & Muito Alto \\
\hline 20 & Havia transparência nos processos e nos resultados da PNH. & 23 & Médio \\
\hline 21 & $\begin{array}{l}\text { A PNH incorporava, satisfatoriamente, as propostas decorrentes da } \\
\text { participação social. }\end{array}$ & 14 & Médio \\
\hline 22 & A PNH possuía, em nível satisfatório, espaços para participação social. & 11 & Médio \\
\hline
\end{tabular}

Fonte: Elaboração própria. 


\section{Conclusões}

Este estudo foi norteado pela seguinte questão: quais contribuições podem ser feitas à PNHIS a partir da análise das etapas do ciclo de políticas públicas? A partir da percepção dos gestores municipais, foi possível compreender o funcionamento (mesmo que parcialmente) da política e identificar pontos críticos e avanços. Ao analisar o aparato institucional pelo qual a PNHIS se sustenta, bem como as organizações e os programas que a compõem, é possível reconhecer que o Governo Federal incluiu a demanda habitacional em sua agenda.

0 fato de os programas apresentarem um foco bem definido em famílias de mais baixa renda é importante, visto que o déficit habitacional brasileiro é composto de 89,6\% dessa parcela da população, enquanto em Minas Gerais esse índice é superior a 90\%.

Ao adotar o pressuposto de que os gestores municipais de habitação conhecem melhor as realidades das famílias residentes em seus municípios, a divergência de opiniões em relação ao fato de os programas habitacionais contemplarem a diversidade das necessidades das famílias e considerarem as especificidades locais pode ser considerada um indicativo de que se necessitam de alterações na concepção dos programas, em suas modalidades de ação. Como será possível a universalização do acesso à moradia digna se os programas adotados não contemplam a diversidade das necessidades das famílias e são inflexíveis de modo a não incorporar as especificidades locais em sua execução?

Nesse sentido, é necessário que as organizações das instâncias de atuação local, como os Conselhos Municipais de Habitação e as prefeituras municipais, elaborem propostas de moradias que incorporem as especificidades da sua região. À medida que as inflexibilidades dos programas federais forem combatidas, essa questão pode ampliar sua representatividade nacional, e, a partir dos debates, pode-se gerar procedimentos viáveis para solucioná-la.

Outro aspecto grave identificado diz respeito ao número de cômodos das moradias construídas não corresponderem às necessidades da composição familiar do grupo que constitui o principal foco da política. Dessa forma, vislumbra-se o risco de investir recursos visando à solução de um problema habitacional que gera a manutenção de outro: o adensamento de pessoas por dormitório. No entanto, compreende-se a complexidade de atender satisfatoriamente à composição familiar, uma vez que os recursos para a execução dos programas e a necessidade de padronizar as construções para viabilização econômico-financeira são fatores limitantes à construção de moradias maiores.

Entende-se que essa questão é multidisciplinar. Não se trata apenas da questão habitacional, mas, antes, refere-se a planejamento familiar, o que, apesar de não se apresentar como demanda social, evidencia que há carências que vão além de bens materiais e dizem respeito à formação das pessoas e das famílias, à educação, à instrução. No entanto, as demandas sociais devem ser tratadas na forma como se apresentam, sendo o número de cômodos das habitações construídas insuficiente para o perfil da sociedade brasileira. Assim, os programas habitacionais devem incorporar a realidade e apresentar modalidades para construção de habitações maiores, com número de cômodos também maior.

A partir das questões analisadas, é possível apontar caminhos para a melhoria da implementação da PNH. Em cinco das nove questões analisadas na etapa de implementação, a instrução e a formação constituíram o ponto de interseção. 0 próprio documento de criação da PNH prevê a incapacidade de o Ministério das Cidades oferecer capacitações para os gestores e servidores municipais trabalharem no âmbito da política habitacional.

0 fato de ser uma política recente, em que os programas sofrem adequações constantes e os instrumentos ainda se encontram em fase de institucionalização, reforça a necessidade de investimento na formação das pessoas. Como sugestão, apresenta-se o estabelecimento de uma rede de instituições envolvidas e interessadas na questão habitacional, como associações, cooperativas habitacionais e universidades. Por meio do método de formação de multiplicadores envolvendo agentes dessas instituições, pode ser possível atingir uma capilaridade maior das capacitações a nível municipal.

0 monitoramento e a avaliação de uma política são etapas essenciais que permitem identificar equívocos desde a concepção dos programas até os resultados de sua implementação. 0 monitoramento 
deve atuar nos pontos de interseção entre uma etapa e outra do ciclo de políticas públicas, a fim de garantir a consistência entre elas.

Ao instituir um sistema de monitoramento e de avaliação, principalmente em políticas sociais abrangentes, no âmbito de um sistema federativo em um país com as dimensões e as diferenças regionais do Brasil, deve-se manter o diálogo com as organizações que participam da implementação da política, cada qual, a partir de sua posição e rede de relações, contribuindo com informações que, em um espaço mais curto de tempo, podem indicar falhas e propor soluções para o desenvolvimento da política. Sugere-se a efetiva instituição do Sistema de Informação, Monitoramento e Avaliação da Habitação.

Como estudos futuros, sugere-se uma investigação quanto à rede de relações que envolvem as ações voltadas para a habitação de interesse social, visando não somente mapeá-la, mas também identificar os atores que possuem maior influência em todas as etapas do ciclo de políticas públicas.

\section{Referências}

Arretche, M., \& Marques, E. (2007). Condicionantes locais da descentralização das políticas de saúde. In G. Hochman, M. Arretche, \& E. Marques (Eds.), Políticas públicas no Brasil. Rio de Janeiro: FIOCRUZ.

Bonduki, N. (2004). Origens da habitação social no Brasil: arquitetura moderna, lei do inquilinato e difusão da casa própria (4. ed.). São Paulo: Estação Liberdade.

Brasil. Ministério das Cidades. (2004). Política Nacional de Habitação. Brasília.

Brasil. Ministério das Cidades. (2010, 23 de julho). Déficit Habitacional 2008. Brasília.

Brasil. Ministério das Cidades. Secretaria Nacional de Habitação. (2011). Déficit habitacional no Brasil 2008. Brasília.

Brasil. Ministério das Cidades. Secretaria Nacional de Habitação. (2012). Programas e ações. Brasília. Recuperado em 4 de fevereiro de 2012, de http://www.cidades.gov.br/habitacao/progrmas-e-acoes-snh

Burger, R. H. (1993). Information policy: a framework for evaluation and policy research. New Jersey: Ablex.

Carneiro, R., \& Souza, J. M. (2007). Moradia popular e política pública na região metropolitana de Belo Horizonte: revisitando a questão do déficit habitacional. In M. Fahel, \& J. A. B. Neves (Eds.), Gestão e avaliação de políticas sociais no Brasil. Belo Horizonte: PUC Minas.

Cunha, E. d., \& Cunha, E. S. (2002). Políticas públicas sociais. In A. E. Carvalho (Ed.), Políticas públicas (pp. 11-25). Belo Horizonte: UFMG.

Draibe, S. M. (2001). Avaliação de implementação: esboço de uma metodologia de trabalho em políticas públicas. In M. C. Barreira, \& M. C. Carvalho (Eds.), Tendências e perspectivas na avaliação de políticas e programas sociais. São Paulo: IEE/PUC-SP.

Drumond, A. M., Silveira, S. D. F. R., \& Silva, E. A. (2014). Predominância ou coexistência? Modelos de administração pública brasileira na Política Nacional de Habitação. Revista de Administração Pública, 48(1), 3-25.

http://dx.doi.org/10.1590/S0034-76122014000100001.

Dye, T. R. (2008). Understanding public policy (12th ed.). New Jersey: Pearson/Prentice Hall.

Easton, D. (1965). A framework for political analisys. Englewood Cliffs: Prentice Hall.

Frey, K. (2000). Políticas públicas: um debate conceitual e reflexões referentes à prática da análise de políticas públicas no Brasil. In Instituto de Pesquisa Econômica Aplicada, Planejamento e políticas públicas (pp. 211-259). Brasília: IPEA.

Jann, W., \& Wegrich, K. (2007). The teories of the policy cycle. In F. Fisher, G. J. Miller, \& M. S. Sidney (Eds.), Handbook of policy analysis: theory, and methods. Florida: CRC Press.

Jenkins, W. (1978). Policy analysis: a political and organizational perspective. Oxford: Blackwell.

Laswell, H. D. (1936). Politics: who gets what, when, how. Cleveland: Meridian Books. 
Lindblom, C. E. (1959). The science of muddling through. Public Administration Review, 19(2), 78-88. http://dx.doi.org/10.2307/973677.

Lindblom, C. E. (1979). Still muddling, not yet through. Public Administration Review, 39(6), 517-526. http://dx.doi.org/10.2307/976178.

Matias-Pereira, J. (2007). Manual de gestão pública contemporânea. São Paulo: Atlas S. A.

Rist, R. C. (1994). Influencing the policy process with qualitative research. In N. K. Denzin, \& Y. S. Lincoln (Eds.), Handbook of qualitative research (pp. 545-557). Thousand Oaks: Sage.

Rua, M. (1997). Análise de políticas públicas: conceitos básicos: Programa de Apoio a Gerência Social no Brasil. Brasília: BID.

Saravia, E. (2006). Introdução à teoria da política pública. In E. Saravia, \& E. Ferrarezi (Eds.), Políticas públicas. Brasília: ENAP.

Secchi, L. (2010). Políticas públicas: conceitos, esquemas de análise, casos práticos. São Paulo: Cengage Learning.

Silva, F. C. (2011). Análise da política de circuitos turísticos de Minas Gerais a partir da perspectiva de policy cycle (ciclo político) (Dissertação de mestrado). Viçosa: Universidade Federal de Viçosa.

Simon, H. (1957). Comportamento administrativo. Rio de Janeiro: Usaid.

Smith, K. B., \& Larimer, C. W. (2009). The public policy theory primer. Philadelphia: Westviem Press.

Souza, C. (2006). Políticas públicas: uma revisão de literatura. Sociologias, (16), 20-45.

http://dx.doi.org/10.1590/S1517-45222006000200003.

Theodoulou, S. Z. (1995). How public policy is made. In S. Z. Theodoulou, \& M. A. Cahn (Eds.), Public policy: the essential readings (pp. 86-96). New Jersey: Prentice Hall.

Yoshimura, M. T. (2004). Análise das tendências de financiamento público para habitação social: o caso de Jaboticabal/SP (Dissertação de mestrado). Universidade Federal de São Carlos, São Carlos.

Editor: Fábio Duarte

Recebido: Dez. 27, 2018

Aprovado: Fev. 16, 2019 